\title{
DANIEL DRAKE'S AETIOLOGICAL VIEWS
}

\author{
by \\ RAYMOND N. DOETSGH
}

IN 1832, Daniel Drake, then professor of clinical medicine in the Medical College of Ohio, and editor, with James C. Finley, of the recently launched Western Fournal of the Medical and Physical Sciences, proposed in a review of the known facts on cholera ${ }^{1}$ an xtiological explanation quite at variance with the prevailing anti-contagionism of the time. ${ }^{2}$ Drake speculated on the possible mode of entry of the causative agent into the victim's body, and so greatly was he impressed with the apparent suddenness of the attack, that he likened the cause to electricity since 'it may penetrate our organs, and by its actual presence exert a deleterious effect. ${ }^{3} \mathrm{He}$ also suggested alternative routes and proposed that either the causative agent may adhere to dermoid or mucoid surfaces, or both, and thereby transmit its influence to the internal parts of the body via the nervous system; or that it may be absorbed through the lungs into the blood and 'circulate as a virus'; or that it may even alter the composition of the blood and render it a poison to the organs it ought to sustain. Drake concluded that, 'the activity of the various organs is reduced, and at the same time perverted. The noxious agent is obviously both sedative and irritating.'

Later in the same year he returned to a detailed consideration of the ætiology of epidemic cholera. ${ }^{5}$ The substance of this work presents a clear view of the xtiological theories prevailing in America at that time. Additionally, a perusal of Drake's arguments discloses that he was in disagreement with most of his contemporaries regarding the ætiology of epidemic disease.

The assumption is made that a disease as widely disseminated and as fatal as cholera must have 'a powerful and pervading remote cause'. An example taken from a paper written at the time will clearly explain the meaning of the last two words:

The causes of disease admit of two chief divisions. The remote, and the immediate or proximate. It may be permitted for our purpose to illustrate these in, the following manner:- A man receives a blow from a stone; the part stricken is bruised; inflammation of the part succeeds. Here the propelled stone is the remote cause of the mischief; the bruise is the proximate cause; and the consequent inflammation forms an array of symptoms, or what is commonly called the disease. In strictness of language, however, we should not call the inflammation, or third stage, the disease itself; it is merely symptomatic of the previous organic change comprised in the second stage. The proximate cause, therefore, is the real disease, the parent of all that follows. ${ }^{6}$

1 Drake, D., 'Epidemic cholera: its pathology and treatment. An eclectic review,' Western J. Med. Phys. Sci., 1832, 5, 593-616; 652-664.

2 Ackerknecht, E. H., 'Anticontagionism between 1821 and 1867,' Bull. Hist. Med., 1948, 22, 562-593.

3 Drake, D., op. cit., p. 609.

4 Ibid., pp. $609-610$.

5 Drake, D., 'Epidemic cholera-its history and aetiology,' Western J. Med. Phys. Sci., 1832, 6, 78-120.

- Anon., 'The nature and cure of the Indian cholera,' Western J. Med. Phys. Sci., 1832, 5, 449-462. See pp. 453-454. A footnote to this article suggests that it was abstracted from some unidentified volume of Englishman's Magazine. 


\section{Raymond N. Doetsch}

At least seven theories concerning the remote cause of epidemic diseases were current in 1832, and Drake critically reviewed each of them in the context of his own experiences and from an analysis based largely upon written reports available at the time.

The 'sol-lunar' hypothesis ascribed epidemic cholera to the influence of the sun and moon. Drake noted that since cholera outbreaks have been found in a great many latitudes and longitudes, and at all phases of the moon, this hypothesis 'would seem to be altogether visionary.' In the same cosmotelluric vein, comets approaching the earth were supposed to exert an effect on the electricity of the atmosphere unfavorable to human life. The mysterious properties of electricity, as well as the more spectacular astronomical occurrences, in this case the expected appearance of Halley's comet in 1835 , could still be invoked as remote causes of epidemic disease. Drake argued that the current outbreak of epidemic cholera had actually commenced in 1817 , and that the comet then approaching the earth was not yet visible in the northern hemisphere where the disease was already raging.

Some attributed cholera to exhalations from the bowels of the earth. Drake did not doubt that 'mineral fermentations' accompanied by the evolution of gases occurred, but he held that conditions on the surface of the earth and not in the strata beneath it governed the progress of cholera. Moreover, the rapid progress of epidemic cholera would have to be equated with an unlikely series of postulated exhalations, and Drake concluded that the 'geological' theory was 'a mere hypothesis unsustained by any positive facts.'

Two other theories involving the atmosphere were also in vogue. The miasmatic theory stated, in essence, that poisonous air ('malaria') was generated by the decomposition of dead animal and vegetable material, assuming proper conditions of heat and moisture were present. Although there seemed to be some correlation between heat, humidity and cholera outbreaks, there were, in fact, many areas wherein cholera did not occur under these conditions. Conversely, cholera epidemics were known to have occurred in dry places of high elevation. Probably for this reason, Drake, in his 1832 writings cautiously, and not too emphatically, turns aside from this explanation. He says, 'We are unable to assent to the miasmatic hypothesis, although so plausibly supported.'

The other atmospheric theory was termed 'insensible meteoration' by Dr. Joseph Mather Smith, professor of the theory and practice of medicine in the College of Physicians and Surgeons of New York. ${ }^{10}$ This theory propounded the view that epidemic cholera was the result of the mode of union, or of the relative proportions of the various atmospheric gases. Smith related it to the 'electric fluid', and Drake's view of Smith's theory is that the latter felt epidemic cholera 'to be the direct result of some disturbance in the equilibrium

7 Drake, D., op. cit., pp. 90-1o6.

8 Ibid., p. 9 I.

I Ibid., p. 92.

10 Dr. Joseph Mather Smith (1789-1866) was intimately involved in epidemic disease outbreaks. He was present at the typhus epidemic in the New York State Prison and in Bellevue Almshouse in 1825, and in three outbreaks of yellow fever. Drake may have read Smith's Elements of the Etiology and Philosophy of Epidemics (1824), or his Epidemic Cholera Morbus of Europe and Asia (1831). 


\section{Daniel Drake's Aetiological Views}

of that fluid, or of electricity and magnetism combined.'11 Alternatively, others considered meteoration to involve a change in the atmosphere, connected in some manner with excesses or deficiencies of oxygen, nitrogen, or carbon dioxide. However, the influence sufficient to incite and continue meteoration was unknown, and although Drake likened the spread of meteoration to the manner in which 'a little leaven leaveneth the whole lump', a particularly apt explanation antedating the work of Schwann, Cagniard de la Tour, and Kützing on fermentation, he concluded that 'such an agent may undoubtedly exist, but as yet the proofs of its reality are altogether conjectural.'12

On the matter of the contagiousness of cholera there were several opinions. A few physicians believed cholera to be highly contagious, independent of environmental conditions, and a few insisted that contagiousness was related to a malarious atmosphere, poor personal hygiene, and other necessary factors. A great majority of the professionals, however, insisted that cholera was noncontagious under all circumstances. The critical point was, and Drake himself emphasized it,

do the bodies of those who labor under Epidemic Cholera, secrete and throw out a poison, either liquid or aerial, which, inhaled or swallowed by a healthy person, will excite the same disease in him, and can he in the same manner, raise it in the system of a third? If so, the malady is contagious, and perpetuates itself by morbid secretion; otherwise, it is not.13, 14

After reviewing the known facts, Drake concluded that the remote cause of cholera, whatever it may be, is comparatively harmless except under special circumstances. His argument is that diseases such as smallpox and itch always propagate themselves in the morbid secretions they generate, and these are effective on almost all persons, whereas in many areas, only a small number are taken with cholera; therefore, if any contagion is associated with this disease, it is less active than that of smallpox, and requires predisposing factors such as enfeebled constitutions, bad habits, poor living conditions, apprehension of the disease, or an impure atmosphere, to become effective. Drake admitted that such a contagion may exist even though direct proof was lacking, but as stated above, in view of the many circumstances requisite for its activity he did not think that it could be very harmful.

Special emphasis was given to auxiliary causes. Drake distinguished two kinds, i.e., those which favour the generation or enhance the activity of the specific remote cause, and, those which predispose the body of the victim to its action. In the first category he placed heat, moisture, decomposable matter, and confined air, contending that where these exist in the highest degree, there exists also the greatest cholera mortality. The auxiliary causes which predispose the body to the remote cause are listed as exhaustion from age,

11 Drake, D., op. cit., p. 92.

12 Ibid., p. 93 .

13 Ibid., p. 93 .

14 In C. E. Rosenberg's The Cholera Years, University of Chicago Press, 1962, it is stated (footnote 22, p. 75): 'a sample of the opinions expressed by 109 American physicians during the years 1832-34 shows that 90 did not consider the disease to be at all contagious, while only 5 considered the disease to be primarily contagious. The other 14 considered it to be primarily non-contagious but admitted that under some circumstances cholera might become communicable (contingent contagionism).' 
chronic infirmities, poor diet, intemperance, long continued exertion, confined lodgings, the habitual breathing of impure air, exposure to the damp and cool atmosphere of the night after the intense heat of the day; irregular and excessive indulgence in food; apprehension of the disease, grief from the loss of friends; and finally, constitutional temperament or native predisposition. Drake maintained that the influence of several, or even one, of these circumstances is so great that one thus placed is likely to become a cholera victim when the disease prevails. He makes an exception of the last condition in that even if an individual is exempt from the action of all the other auxiliary causes, he may yet take the disease if his system has a native predisposition to the action of the remote cause.

We come then, to the last hypothesis, namely, the animalcular. It was, of course, not a new theory, and Drake quoted the work of Dernham, Baker, Réaumur, ${ }^{15}$ and others concerning the nature and habits of insects too minute to be seen with the naked eye ('animalcules'). In this context, Cotton Mather and John Crawford ${ }^{16}$ were the only two Americans, prior to Drake, who speculated on this possibility, but neither one is cited. Drake suggested that there could exist poisonous animalcules, perhaps of the nature of mosquitoes or gnats, that were the cause of epidemic cholera. In so doing he could account for the greater prevalence of the disease in hot climates, and in marine and humid circumstances. Additionally, simultaneous outbreaks in various locations could be explained, as well as the sudden beginning, and short duration of the disease. Finally, Drake said,

... the doctrine still further explains, why exposure to a damp, and especially the evening air, has been found so productive of the disease-as the animalculae, may from analogy, be presumed to be then most abroad; why so many persons are attacked in the latter part of the night, particularly if exposed to the atmosphere of the evening; why a night breeze from the shore in hot countries, blowing upon a vessel lying near, has sometimes been followed in a few hours by malignant cholera, in a great number of those exposed to it; why persons residing in low, damp, filthy, and ill-ventilated places are more affected than others-for in such situations the insects would multiply rapidly, and no cause would operate to disperse them $\ldots{ }^{17}$

The animalcules were supposed to produce eggs ('ova') that would either float in the air, or fall in water and thus be inhaled or swallowed. They would adhere to the mucous membrane, or be absorbed into the blood of the victim, and ultimately develop into insects. Drake did not elaborate on the mechanism whereby the insects, once hatched in the body, would cause the disease, but his entire argument is reminiscent of that used twenty-six years earlier by the forgotten Crawford. It is entirely probable that Drake was not completely convinced of the correctness of his hypothesis. He concluded his 1832 work with the statement that although the animalcular theory explains more of the facts of cholera than any other theory this does not establish its truth. Nevertheless, he admonishes his colleagues for adopting dogmatic positions con-

15 Drake, D., op. cit., p. $96 \mathrm{ff}$.

16 Doetsch, R. N., 'John Grawford and his contribution to the doctrine of contagium vivum,' Bacteriol. Rev., 1964, 28, 87-96.

17 Drake, D., op. cit., pp. 102-103. 


\section{Daniel Drake's Aetiological Views}

cerning one of the other hypotheses, and he hopes the animalcular hypothesis will 'excite doubts and refresh the spirit of inquiry.'

In December of $183_{2}$ Drake reprinted with emendations the papers originally appearing in the Western Fournal (a total of 46 pages) in a booklet entitled $A n$ Account of the Epidemic Cholera as it Appeared in Cincinnati. ${ }^{18}$ No new ætiological theory appeared here, although he says epidemic cholera sometimes spreads by contagion. The general conclusion was that the facts furnished by the Cincinnati epidemic were altogether of a negative character and demonstrated only that it did not originate from the atmosphere, or miasma, or meteoration.

In 1850 Drake's masterpiece, A Systematic Treatise, Historical, Etiological, and Practical on the Principal Diseases of the Interior Valley of North America, etc., ${ }^{19}$ was published. Here, after a lapse of eighteen years, he returned to 'speculations' on the efficient cause of disease, in this case autumnal fever. The latter was most probably not a single disease entity, and my impression is that what is described was principally a mixture of typhoid and malaria. Drake says,

in different parts of the Interior Valley, the fevers which we are about to study, are known under the names-autumnal, bilious, intermittent, remittent, congestive, miasmatic, malarial, marsh, malignant, chill-fever, ague, fever and ague, dumb ague, and lastly, the Fever ... I shall use the epithet autumnal, as involving no etiological or pathological hypothesis; and at the same time, including every modification ...20

The number of ætiological hypotheses considered were reduced from seven to three, namely, the meteoric, the malarial, and the vegeto-animalcular. In reviewing their merits, Drake evidences a much keener critical faculty than he did in his 1832 publications, since, of course, preparation of the Treatise did much to enlarge his fund of knowledge. In the meteoric hypothesis, the cause of the disease was ascribed to the direct and combined action of a hot, humid, and electrical atmosphere. In arguing against this theory Drake pointed out that since its advocates denied the necessity of a poison in the atmosphere, and since he has shown previously that neither heat nor moisture, by itself, can produce fever, the only possibility remaining arises from a combination of the last two factors. Drake gives examples of situations wherein almost identical combinations of moisture and temperature occur in localities suffering from and others free from fever. He shows also that the fever occurs in some areas of low humidity, whereas in salt works the employees spend their working days in a hot and humid atmosphere, but are generally exempt from the fever. He concluded that these examples are sufficient to rule out the meteoric hypothesis, except insofar as certain atmospheric conditions may act as exciting causes.

The alternative was to postulate that a deleterious agent does, in fact, exist

18 Drake, D., An Account of the Epidemic Cholera, as it Appeared in Cincinnati, Cincinnati, O. E. Deming, $1832,46 \mathrm{pp}$.

19 Drake, D., A Systematic Treatise, Historical, Etiological, and Practical, on the Principal Diseases of the Interior Valley of North America as They Appear in the Caucasian, African, Indian, and Esquimau Varieties of its Population, Cincinnati, O. W. B. Smith, 1850, 894 pp. In 1854, a 'second series' was published posthumously under the editorial guidance of S. Hanbury Smith and Francis G. Smith by Lippincott, Grambo and Co. of Philadelphia. This 985 page volume duplicates the sections under consideration here, and as a matter of fact, the last 175 pages of volume I are reprinted in the first part of volume II.

20 Ibid., p. 703. 


\section{Raymond N. Doetsch}

in the atmosphere, and this must be either an inorganic poison (malaria) or an organic agent (animalcular).

In Drake's time the word 'malaria' was equivalent to 'miasm'. It meant any emanation from decomposing animal or vegetable substance, or from the earth in marshy situations, which had a morbid effect on those exposed to it. Drake admitted that the fever generally prevailed where the organic matter was most abundant in the soil, and further, that a temperature above $60^{\circ} \mathrm{F}$. was necessary to maintain the processes of fermentation and putrefaction. He also noted that in areas under long and continued cultivation, which exhausted the organic matter of the soil, the fever almost ceased to appear. He concluded from these observations that there was a connection between a certain surface condition and autumnal fever, but that this did not prove the existence of a gas which would be the efficient cause.

There remained, then, only the vegeto-animalcular hypothesis. In the eighteen years since Drake first proposed the animalcular hypothesis of cholera, a number of pertinent discoveries and observations had been made. The work of the 'Ehrenberg School' appealed to Drake as making this hypothesis more probable, and although he had neither the time nor means for experimental or bibliographical inquiry, he regarded the hypothesis of animalcules as more plausible than that of vegetable germs in regard to cholera. This attitude was identical to that of Mitchell, ${ }^{21}$ and is to be distinguished carefully from an anti-contagionist stand. The point is that living invisible insects are postulated to cause disease rather than living 'vegetable germs'. Drake held that the history of autumnal fever could be more successfully explained by the vegetoanimalcular hypothesis than by any other theory. He wrote, 'I have united words to express an hypothesis which ascribes autumnal fever to living organic forms, too small to be seen with the naked eye; and which may belong either to the vegetable or animal kingdom, or partake of the characters of both.'22 This meant that, in contrast to his views on cholera ætiology, either animalcules or vegetable germs could be assumed to be the efficient cause of autumnal fever.

The efficient cause was endowed with properties supposedly similar to 'narcotico-irritating gases', or certain solid and fluid bodies, which, 'in large doses, destroy life suddenly, by reducing power, and in smaller portions, weaken while they pervert the functions.' ${ }^{23}$ Upon entering the body this agent would be absorbed by the blood with a resultant deterioration of that fluid, and of necessity the entire internal surface of the arteries, veins, and heart also would come in contact with it. The first stage of autumnal fever, with its 'reduction of vital energy, obtuseness of sensibility, suspended or prevented secretion, and diminished calorification ... will be felt in all parts of the body, because the agent which produces them travels with the circulation.' ${ }^{24}$ This, in brief, was Drake's concept of the mode of action of the efficient cause.

It is most surprising, indeed, to find that Drake did not attach much practical

21 Doetsch, R. N., 'Mitchell on the cause of fevers,' Bull. Hist. Med., 1964, 38, $241-259$.

22 Drake, D., op. cit., p. 723.

23 Ibid., p. 732.

24 Ibid., p. 733. 


\section{Daniel Drake's Aetiological Views}

importance to the discovery of the efficient cause of autumnal fever. In fact, his discussion of ætiology was made, as he says in his Treatise (pp. 727-728), largely out of deference to his fellow physicians, rather than to his own conviction as to the value of such a discovery. $\mathrm{He}$ argued that even if the meteoric condition, or gas, or microorganism responsible for causing the fever were known, there would still be no way to defend oneself from it. Further, he felt that knowing the nature of the efficient cause would be of little use in treatment, and he explains that in the case of hydrophobia the cause (I assume he refers to the fact that it is transmitted mainly by dog bites) is known but the disease cannot be cured, and that in the case of goitre, the reverse is true. Nevertheless, after all this pessimistic argument, he concluded, ignorant, however, as we are of any definite efficient cause for autumnal fever, I am a full believer in its existence, and shall speak of it as a specific agent, known only by its effects on the living body.' ${ }^{25}$

Drake was, however, more involved in ætiological considerations than he realized, and it is not by chance that he entitled the first chapter of his Treatise 'General Etiology'. He distinguished between diseases occurring independently of all known external influences and among all races, such as cancer, cataract, and apoplexy, and those which occur only in certain localities such as yellow fever, or goitre. Drake felt that physical causes lay at the bottom of whatever differences were seen in the same diseases of different parts of the earth, and he designated this as 'climatic etiology'. The effects of climate could be exciting or predisposing, that is, sudden changes were believed to act as exciting causes of disease, whereas a long-continued climate might bring about physiological changes predisposing one to a particular disease. In addition, climatic influences would be classed as 'direct' if the effect was immediate, or 'indirect' if the effect was cumulative. Drake also maintained that climatic changes could cure certain diseases whereas in other cases such changes completely impeded their cure. 'Climate' as used by Drake was meant to express states of the atmosphere such as its heat, light, electricity, vapour, fog, mist, cloud content, its dews, rain, hail, frost, and snow, weight, density, its movements and winds, its gases and mechanical properties, all of which were (or could be) different in different times or places.

What evaluation can one make of these views? Was Drake an isolated American contributor to contagionist ætiological theory, far in advance of his colleagues, or was he simply being perverse in not 'going along with' the generally accepted explanations of his day?

There is no doubt that most, if not all, physicians of the time believed in predisposing causes of disease, and Drake was in agreement with this. However, most physicians tended toward atmospheric theories to explain cholera ætiology, particularly since they were less rigid in their tenets than any they based upon animalcules. Furthermore, the atmospheric theories militated strongly against use of quarantine, and the 'antisocial' doctrine of contagion.

25 Ibid., p. 728. 


\section{Raymond N. Doetsch}

It seems then, that Drake almost alone held his singular views on cholera ætiology. It has been pointed out that Drake's predecessor, John Crawford, had fostered similar views as early as 1806 , but for a variety of reasons, scientific and philospohical, these had failed to impress the American physicians of his day. Rosenberg ${ }^{26}$ argues that the animalcular theory of 1832 was 'merely a variation of standard atmospheric ideas, differing in that the cholera-causing substance in the air was specified as being a 'small winged insect not visible to the naked eye'.

The impossible task for Drake was a scientific demonstration of his views. This he could not perform, and consequently his analogical arguments were as unconvincing as those of Crawford, or indeed of Drake's contemporary, John Kearsley Mitchell. ${ }^{27}$ It is interesting to observe that although both Crawford and Drake were contagionists in an anticontagionist milieu, they neither of them believed in the efficacy of quarantine in controlling epidemics. Furthermore, Drake held that Asiatic cholera was but an aggravated form of 'cholera morbus', thus implying a local origin and therefore not contagious. There is, finally, Drake's pessimism regarding the value of discovering the causative agent of cholera. He failed completely to see how control could be effected once a living agent was implicated. The example he used of citing the cure of scurvy without knowing its cause was ill chosen, not only because it was based on analogy, but because it grossly underestimated the value of knowing the life history of any living infectious agent, and thereby being able to deal with it directly at any stage in its development. Perhaps in Drake's time this was not so evident as it is today.

There was value in Drake's analysis of the current ætiological theories of his day in that he clearly perceived and pointed out the weakness in each of them. He realized the need for experimental work, and the importance of laboratory work like Ehrenberg's towards an eventual solution of the problem. In this regard, he certainly was in the vanguard of the physicians of his time. On the other hand, there is little evidence of intellectual progression in Drake's thinking on the problem between $183^{2}$ and 1850 .

As the American pioneers moved rapidly westward, medical considerations were often left to follow when they could. In the turmoil and clash with the wilderness, and all its terrible elements, Drake literally sprang up in its midst. His pioneer spirit, manifested in so many different ways, is evident by his presence among the few contagionists of his time. The variety and pressure of the events in Drake's busy life of necessity restricted his development of a sound ætiological explanation of epidemic disease, based upon contagionist doctrine, to the barest of details. Much more would have to be accomplished than Drake could do, even if he had ample time at his disposal. It is interesting

20 Rosenberg, C. F., op. cit., p. 78.

27 In a footnote of Drake's Treatise (p. 727) there appears the following: 'When this article (meaning the Treatise) was about to be sent to the press, a friend handed me Professor Mitchell's Lectures on the Croptogamous Origin of Malarious and Epidemic Fevers, which I had not seen before. The array of facts made by the learned author, seems almost irresistible; and, from his distinguished reputation, it will, no doubt, lead many others into new courses of observation and experiment.' 


\section{Daniel Drake's Aetiological Views}

to observe, however, that there is in the history of contagionist theory in America a recurring attempt to establish it as an xtiological doctrine on purely analogical grounds. Thus one finds that Drake's work brings us near the end of the line that began with Mather, over two hundred years before him.

\section{ACKNOWLEDGMENT}

This work was supported in part by a grant (GS-64) from the National Science Foundation, Division of Social Sciences, History, and Philosophy of Science. The author wishes to acknowledge his appreciation for a leave of absence granted by the University of Maryland in order to carry out the work presented here at the Institute of the History of Medicine, Johns Hopkins University, Baltimore, Maryland. 